\title{
Identification of Heat-Treated Sapphires from Sri Lanka: Evidence from Three-Dimensional Fluorescence Spectroscopy
}

\author{
Yuyang Zhang $\mathbb{D}$ and Meihua Chen *
}

check for

updates

Citation: Zhang, Y.; Chen, M.

Identification of Heat-Treated

Sapphires from Sri Lanka: Evidence

from Three-Dimensional

Fluorescence Spectroscopy. Crystals

2022, 12, 293. https://doi.org/

$10.3390 /$ cryst 12020293

Academic Editors: Fei Liu, Taijin Lu and Tingting $\mathrm{Gu}$

Received: 29 January 2022

Accepted: 15 February 2022

Published: 19 February 2022

Publisher's Note: MDPI stays neutral with regard to jurisdictional claims in published maps and institutional affiliations.

Copyright: (C) 2022 by the authors. Licensee MDPI, Basel, Switzerland. This article is an open access article distributed under the terms and conditions of the Creative Commons Attribution (CC BY) license (https:// creativecommons.org/licenses/by/ $4.0 /)$.
Gemmological Institute, China University of Geosciences, Wuhan 430074, China; gembubble@cug.edu.cn

* Correspondence: mhchengp@126.com

\begin{abstract}
Heat treatment is an important method used to improve the value of sapphires. The identification of heat-treated sapphires is a significant and challenging subject in gemology. In this study, natural sapphire samples from Ratnapura, Sri Lanka, were heated at different temperatures from $900^{\circ} \mathrm{C}$ to $1500^{\circ} \mathrm{C}$. Then, the samples were examined by FTIR and three-dimensional fluorescence spectrometry. When excited by $450 \mathrm{~nm}$ light, most natural samples emitted a fluorescence band between $540 \mathrm{~nm}$ and $560 \mathrm{~nm}$. This fluorescence disappeared after low-temperature heat treatment. Therefore, the presence of fluorescence between $540 \mathrm{~nm}$ and $560 \mathrm{~nm}$ is evidence of unheated sapphires from Sri Lanka. Almost all of the samples emitted fluorescence centered at $470 \mathrm{~nm}$ after hightemperature treatment. Therefore, fluorescence at $470 \mathrm{~nm}$ indicates that the sapphires from Sri Lanka were treated at a high temperature. Three-dimensional fluorescence spectroscopy can serve as a method to identify heat-treated sapphires.
\end{abstract}

Keywords: sapphire; heat treatment; spectroscopy characteristics; three-dimensional fluorescence spectroscopy

\section{Introduction}

Sapphires are a variety of the mineral corundum, mainly composed of $\mathrm{Al}_{2} \mathrm{O}_{3}$. Their lustrous and colorful appearance, excellent durability and long mining history make them one of the most valuable gems in the market. However, most natural specimens cannot be used for this purpose due to the low quality of their color. To improve their color and greatly enhance their commercial value, sapphires are treated with different methods, among which heat treatment is the most important. Taking the melting temperature of rutile needle inclusion $\left(1200-1350^{\circ} \mathrm{C}\right.$ ) as the boundary, the heat treatment of sapphires is divided into low-temperature (below $1200{ }^{\circ} \mathrm{C}$ ) and high-temperature heat treatment (above $\left.1350{ }^{\circ} \mathrm{C}\right)[1]$.

Due to the huge difference in commercial value between natural and treated sapphires, it is important for gem laboratories to identify whether sapphires submitted by customers have been treated. However, this identification is challenging. The classical characteristics of heat-treated sapphires include stress fractures, residual sodium borate and chalky fluorescence. The application of spectroscopic technology has shown that absorption peaks of $3309 \mathrm{~cm}^{-1}$ and $3232 \mathrm{~cm}^{-1}$ in the FTIR spectrum could be evidence of heat treatment [1]. However, key evidence of heat treatment can be difficult to find due to different sample properties and treatment conditions. Therefore, gemologists are looking for more effective identification methods. The key piece of evidence that allows gemologists to identify heattreated sapphires is the presence of an anomalous chalky fluorescence [2], which indicates that it is possible to explore evidence of heat treatment in sapphires using fluorescence. In this research, we used traditional methods (photomicrograph and FTIR) and fluorescence spectroscopy to obtain characteristics of sapphires before and after heat treatment, finding new evidence of heated sapphires. 


\section{Materials and Methods}

\subsection{Materials}

Six sapphire samples from a metamorphic-related placer in Ratnapura, Sri Lanka [3], were selected for study in this research. Regional and/or contact metamorphism favored the formation of corundum by removing silica and water, transforming aluminum- and magnesium-bearing silicates into oxides [3]. Sapphires from alluvial deposits in Ratnapura have been transported long distances, so they are usually rounded pebbles. Historically, sapphires from these deposits have been an important mineral resource, but most of them must be heat-treated to be used in jewelry.

Rough stones were cut into six $2 \mathrm{~mm}$ slices along the approximately vertical C-axis direction to reduce the influence of crystallographic orientation and crystal habit on the results. Photos were taken with a Nikon D810 camera (Figure 1). The general gemological properties of samples are listed in Table 1. All of these samples are pale blue-colorless and will need to be heated to improve their color.

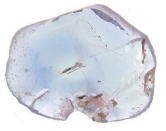

BG2-1

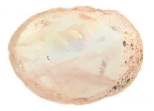

DG2-1

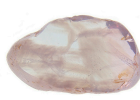

BG4-1

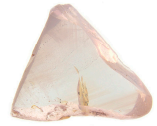

SG3-1

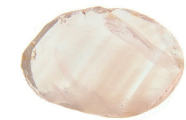

DG1-1

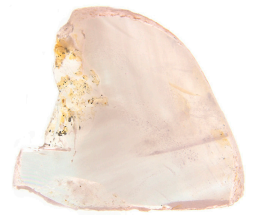

SG3-2

$5 \mathrm{~mm}$

Figure 1. The studied sapphire samples.

Table 1. General gemological properties.

\begin{tabular}{ccccc}
\hline Sample No. & Specific Gravity & Refractive Index & Color & Transparency \\
\hline BG2-1 & 3.98 & $1.762-1.770$ & pale blue & transparent \\
BG4-1 & 3.98 & $1.762-1.770$ & colorless & transparent \\
DG1-1 & 3.97 & $1.761-1.769$ & colorless & transparent \\
DG2-1 & 3.98 & $1.762-1.770$ & colorless & transparent \\
SG3-1 & 3.97 & $1.761-1.769$ & colorless & transparent \\
SG3-2 & 3.99 & $1.763-1.771$ & colorless & transparent \\
\hline
\end{tabular}

\subsection{Methods}

Photomicrographs of the inclusions in the samples were taken using a Leica DFC 550-Leica M205 A Microphotographic system (Leica, Weztlar, Germany).

Chemical analysis was performed using a GeoLas 2005-Agilent 7500a LA-ICP-MS (Agilent, Santa Clara, CA, USA) with a $44 \mu \mathrm{m}$ beam spot and a frequency of $6 \mathrm{~Hz}$.

Infrared spectra of all samples were obtained using a Bruker Vertex 80 Fouriertransform infrared (FTIR) spectrometer (Bruker, Ettlingen, Germany). The transmittance method was used, with the following parameters: 64 scans, $1800-4000 \mathrm{~cm}^{-1}$ range, and $4 \mathrm{~cm}^{-1}$ resolution.

The UV-Vis spectra were detected by the Skyray Gem 100 (Skyray, Suzhou, China). The test range was 220-1000 nm, and the light sources were a tungsten lamp and a xenon lamp.

The fluorescence emission spectra and three-dimensional fluorescence spectra of all samples were obtained using a JASCO FP8500 fluorescence spectrometer (JASCO, Ishikawamachi Hachioji-shi Tokyo, Japan) with the following parameters: Ex bandwidth$5 \mathrm{~mm}$, Em bandwidth-5 mm, PMT voltage-600V, and scan speed-2000 nm/min. 
The equipment used for heat treatment was the GSL-1700X high-temperature tube furnace (HF-Kejing, Hefei, China). A low-temperature oxidation atmosphere was used to reduce the blue hues of sapphires, while a high-temperature reduction atmosphere was used to enhance the blue hues. Therefore, this experiment divided the heat treatment conditions into four groups using low-temperature oxidation treatments and one group using a high-temperature reduction treatment (Table 2).

Table 2. Heat treatment scheme.

\begin{tabular}{cccc}
\hline $\begin{array}{c}\text { Maximum Temperature } \\
\left({ }^{\circ} \mathbf{C}\right)\end{array}$ & $\begin{array}{c}\text { Heating Rate } \\
\left({ }^{\circ} \mathbf{C} / \mathbf{m i n}\right)\end{array}$ & $\begin{array}{c}\text { Heat Treatment Time } \\
\mathbf{( h )}\end{array}$ & $\begin{array}{c}\text { Atmosphere } \\
900\end{array}$ \\
1000 & 5 & 12 & oxidation \\
1100 & 5 & 12 & oxidation \\
1200 & 5 & 12 & oxidation \\
1500 & 5 & 16 & oxidation \\
reduction
\end{tabular}

\section{Results and Discussion}

\subsection{Properties of Unheated Sapphire Samples}

\subsubsection{Chemical Analysis}

The quantitative chemical composition, which was obtained with LA-ICP-MS, is shown in Table 3. The main component of the samples was $\mathrm{Al}_{2} \mathrm{O}_{3}$, which is in accordance with the composition of corundum. Moreover, low concentrations of Fe and Ga indicated that these samples were metamorphic-related corundum.

Table 3. Chemical composition of samples obtained by LA-ICP-MS.

\begin{tabular}{ccccccc}
\hline & BG2-1 & BG4-1 & DG1-1 & DG2-1 & SG3-1 & SG3-2 \\
\hline $\mathrm{Al}_{2} \mathrm{O}_{3}$ & 99.35 & 98.97 & 99.32 & 99.47 & 99.27 & 99.02 \\
$(\mathrm{wt} \%)$ & 163 & 243 & 137 & 148 & 204 & 247 \\
$\mathrm{Fe}($ ppma) & 72 & 159 & 63 & 87 & 144 & 209 \\
$\mathrm{Ti}$ (ppma) & 179 & 72 & 91 & 113 & 191 \\
$\mathrm{Mg}$ (ppma) & 64 & 74 & 7 & 35 & 24 \\
$\mathrm{Ga}$ (ppma) & 29 & 14 & 7 & &
\end{tabular}

\subsubsection{Infrared Spectroscopy Features}

The FTIR spectra of samples are shown in Figure 2. All samples showed peaks at $2300-2400 \mathrm{~cm}^{-1}, 2916 \mathrm{~cm}^{-1}$ and $2851 \mathrm{~cm}^{-1}$. The $2300-2400 \mathrm{~cm}^{-1}$ peak was assigned to $\mathrm{CO}_{2}$ in the environment. The $2916 \mathrm{~cm}^{-1}$ and $2851 \mathrm{~cm}^{-1}$ peaks were assigned to the stretching vibrations of $\mathrm{CH}$ [4], which may originate from organic matter filling the surfaces or fissures of the samples.

Sample DG2-1 showed $2123 \mathrm{~cm}^{-1}$ and $1994 \mathrm{~cm}^{-1}$ peaks, which indicated the presence of diaspore [5]. The cause of $3309 / 3232 \mathrm{~cm}^{-1}$ peaks is believed to be related to $\mathrm{OH}$ [1], but none of the samples investigated in this work showed this absorption peak. 


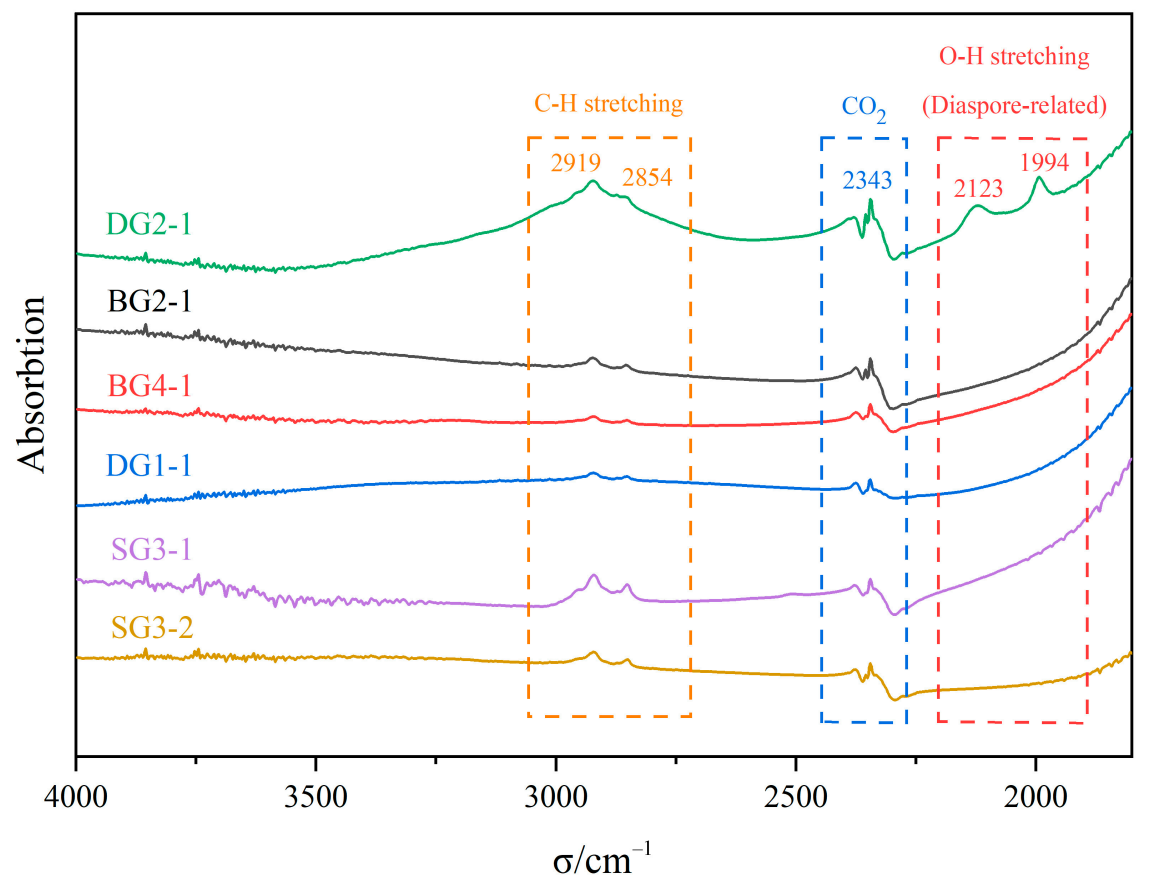

Figure 2. Infrared spectra of sapphire samples.

\subsubsection{UV-Vis Spectroscopy Features}

The UV- Vis spectra of samples are shown in Figure 3. Sample BG4-1 displayed peaks at $388 \mathrm{~nm}$ and $450 \mathrm{~nm}$. The other five samples showed a $450 \mathrm{~nm}$ peak but no $388 \mathrm{~nm}$ peak. The $388 \mathrm{~nm}$ peak was assigned as $\mathrm{Fe}^{3+}$, and $\mathrm{Fe}^{2+}-\mathrm{Fe}^{3+}$ led to absorption at $450 \mathrm{~nm}[6,7]$

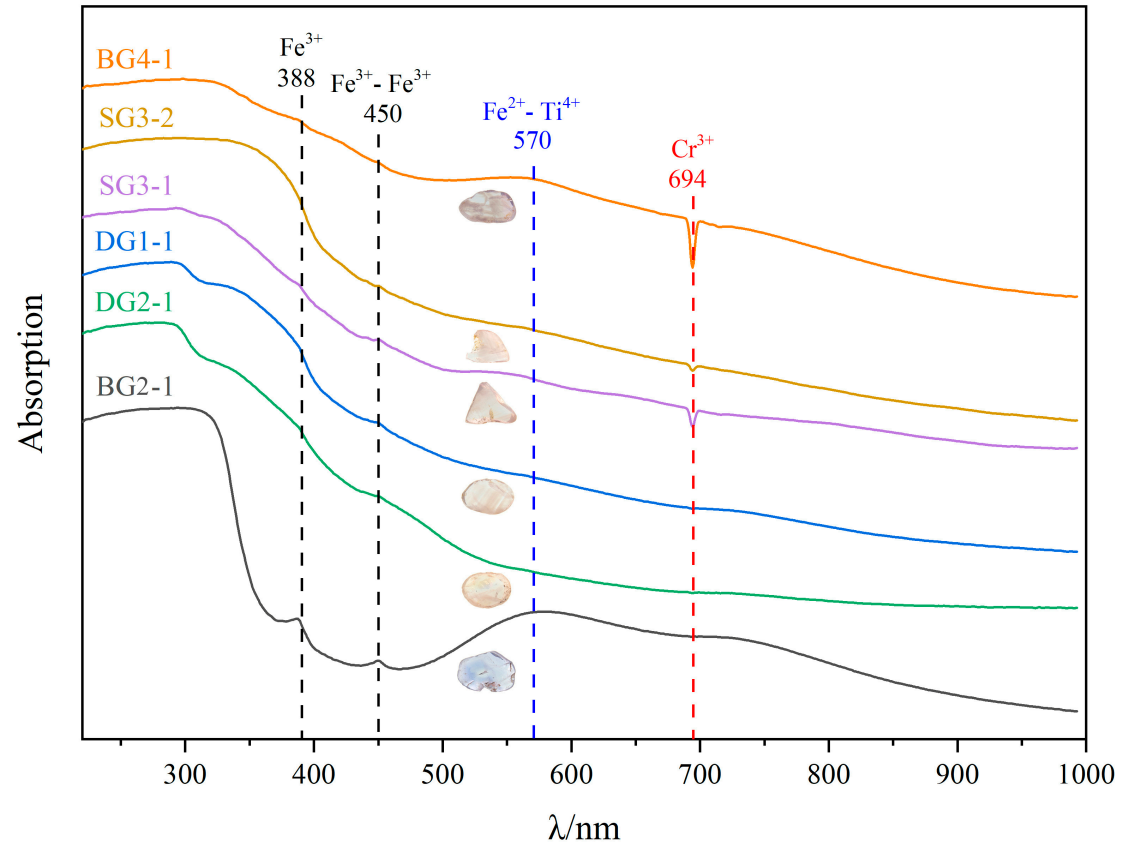

Figure 3. UV-vis spectra of the sapphire samples.

Samples BG2-1 and BG4-1 showed a wide absorption peak near $570 \mathrm{~nm}$. The other samples had no obvious absorption. This absorption peak was produced by $\mathrm{Fe}^{2+}-\mathrm{Ti}^{4+}$, and is the main cause for the blue color of sapphires.

Samples BG4-1, SG3-1 and SG3-2 showed a Cr ${ }^{3+}$-related peak at $694 \mathrm{~nm}$ [8]. 


\subsection{Fluorescence Features of Sapphire Samples}

3.2.1. Fluorescence Excited by $365 / 254$ nm UV Lamp

Samples BG4-1, SG3-1 and SG3-2 showed weak red fluorescence when excited by the $365 \mathrm{~nm}$ UV lamp. Other samples were inert under the same conditions. This reaction was consistent with UV-vis spectra. All samples were inert when excited by the $254 \mathrm{~nm}$ UV lamp.

\subsubsection{Three-Dimensional Fluorescence Spectroscopy Features}

Three-dimensional fluorescence spectroscopy (3D fluorescence spectroscopy) is widely used in biology, chemistry, mineralogy and gemology. It magnifies the contrast between the signal and background and completely filters out the excitation light source without blocking the fluorescence emitted by the sample, which makes weak fluorescence clearly visible [9]. For example, the use of fluorescence spectroscopy can effectively distinguish whether pearls have been brightened [10] or dyed [11], and can also provide evidence regarding the origin of amber [12].

The 3D fluorescence spectra of the samples are shown in Figure 4 and are as follows:

(1) Except for DG1-1, the samples showed $420-440 \mathrm{~nm}$ fluorescence when excited by the $360 \mathrm{~nm}$ light source. The fluorescence in this range was assigned to the charge transfer of $\mathrm{O}^{2-}-\mathrm{Ti}^{4+}$. The fluorescence was located at $415 \mathrm{~nm}$ when the concentration of $\mathrm{Ti}^{4+}$ was low. With the increase in $\mathrm{Ti}^{4+}$ concentration, this fluorescence shifted to a longer wavelength position [1].

(2) Except for BG2-1, the samples showed obvious 540-560 $\mathrm{nm}$ fluorescence when excited by the $450 \mathrm{~nm}$ light source. All six samples emitted 560-580 $\mathrm{nm}$ fluorescence when excited by the $320 \mathrm{~nm}$ light source.

(3) Samples BG4-1, SG3-1 and SG3-2 displayed strong $694 \mathrm{~nm}$ fluorescence when excited by the $410 \mathrm{~nm}$ and $550 \mathrm{~nm}$ light sources. The $694 \mathrm{~nm}$ fluorescence excited by $410 \mathrm{~nm}$ was assigned to ${ }^{4} \mathrm{~A}_{2}-{ }^{4} \mathrm{~T}_{1}$ of $\mathrm{Cr}^{3+}$, while the fluorescence excited by $550 \mathrm{~nm}$ was assigned to ${ }^{4} \mathrm{~A}_{2}-{ }^{4} \mathrm{~T}_{2}$ of $\mathrm{Cr}^{3+}[8,13]$. Samples that emitted $694 \mathrm{~nm}$ fluorescence were consistent with the UV-vis spectra. The reason why the fluorescence peaks of samples DG1-1 and BG2-1 were not completely consistent with the other samples is currently unclear.

The fluorescence near $460 \mathrm{~nm}$ (emission wavelength) can be attributed to the inherent error of the instrument. The abrupt change near $540 \mathrm{~nm}$ (emission wavelength) was caused by raster conversion.

In order to more clearly identify the peaks of various fluorescence, light sources with wavelengths of $320 \mathrm{~nm}, 360 \mathrm{~nm}, 410 \mathrm{~nm}$ and $450 \mathrm{~nm}$ were selected to excite the samples and plot the emission spectra (Figure 5). Most samples emitted fluorescence at $420 \mathrm{~nm}, 460 \mathrm{~nm}$, $550 \mathrm{~nm}$ and $570 \mathrm{~nm}$. Samples BG4-1, SG3-1 and SG3-2 showed fluorescence at $694 \mathrm{~nm}$. 

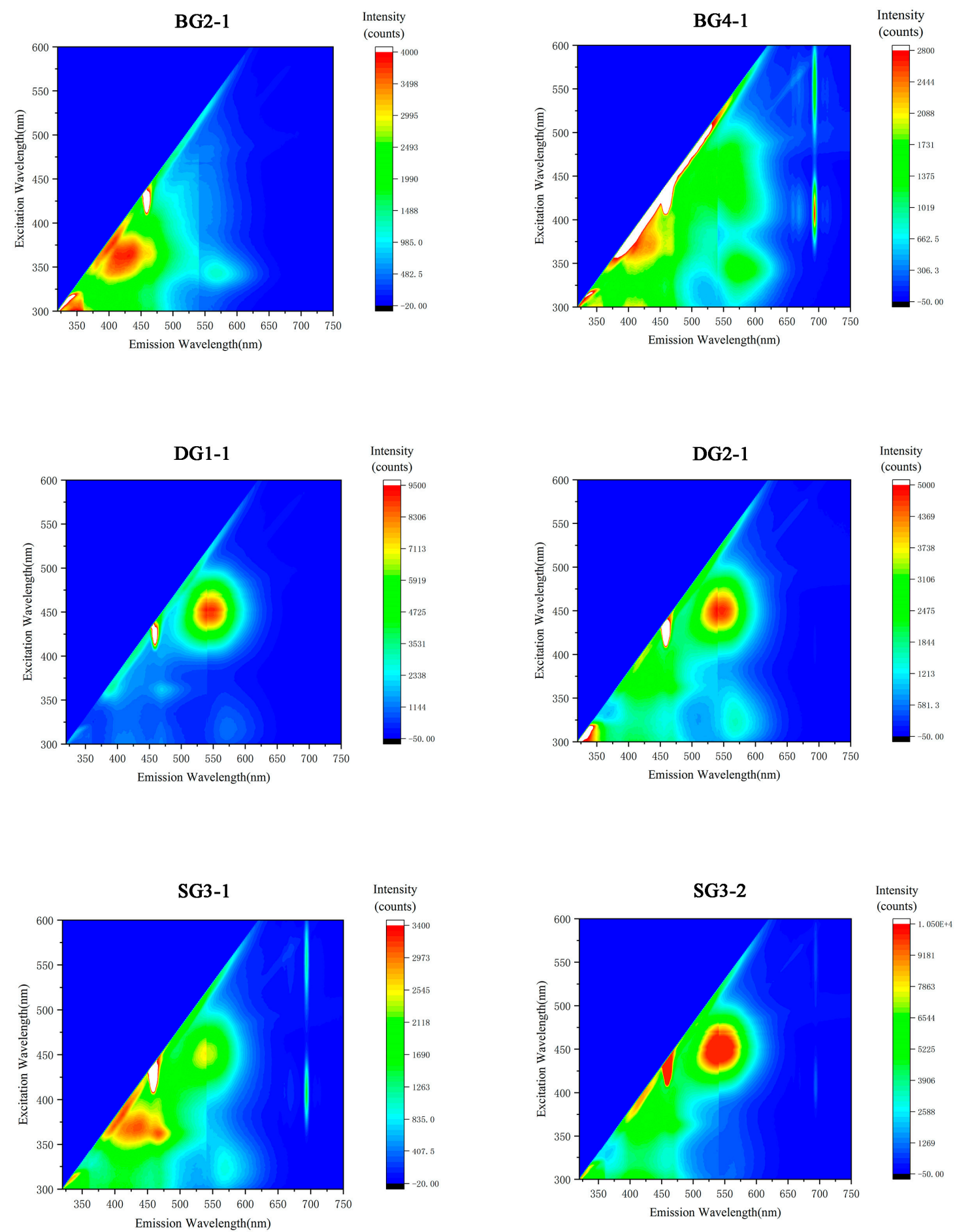

Figure 4. The 3D fluorescence spectra of the sapphire samples. 
(a)

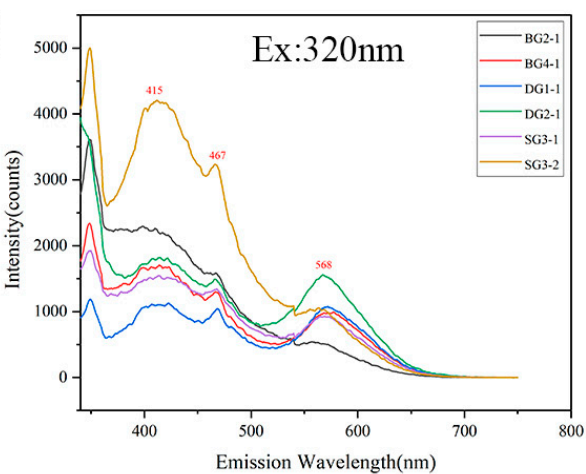

(c)

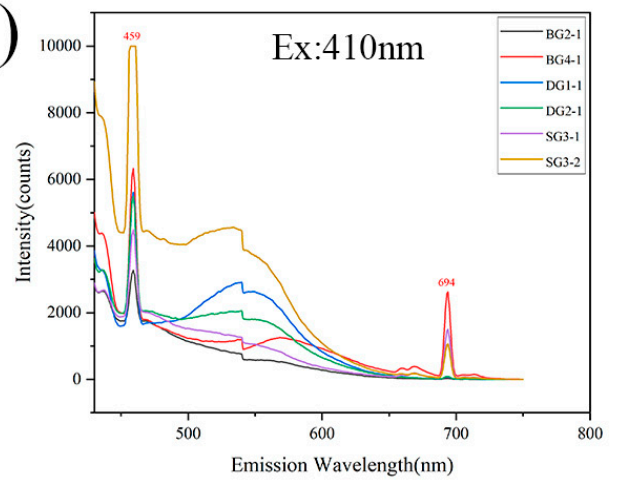

(b)

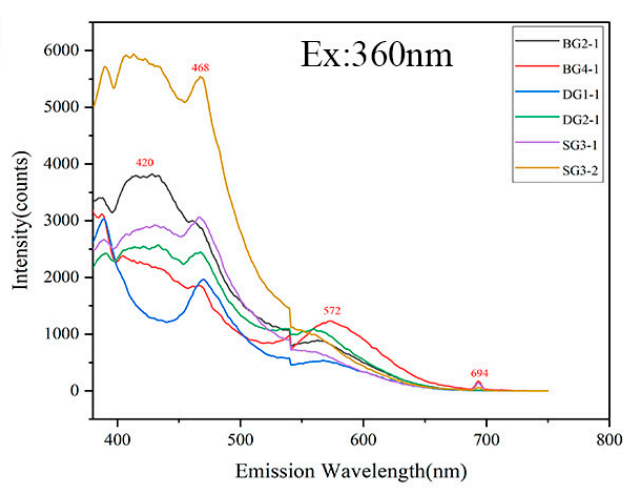

(d)

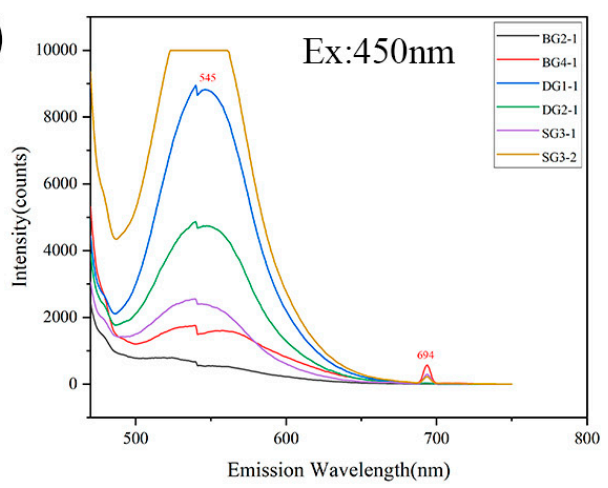

Figure 5. Emission spectra of the sapphire samples excited by a (a) $320 \mathrm{~nm}$, (b) $360 \mathrm{~nm}$, (c) $410 \mathrm{~nm}$ and (d) $450 \mathrm{~nm}$ light source.

As shown in Figure 5, the excitation efficiency for each luminescent center was different when different excitation sources were used. This indicates that some important information may be missed when observing fluorescence under a $365 \mathrm{~nm} / 254 \mathrm{~nm}$ UV lamp, while by using three-dimensional fluorescence it is possible to discover the luminous centers of gems comprehensively and in more detail.

\subsection{Properties of Heated Sapphire Samples}

\subsubsection{Appearance and Inclusion Features after Heat Treatment}

To compare the color changes of the sapphire samples after heat treatment under different conditions, images were taken with a Nikon D810 camera in a D65 light box, and color correction was performed with an X-Rite gray plate (Figure 6).

After heat treatment at $900{ }^{\circ} \mathrm{C}, 1000{ }^{\circ} \mathrm{C}, 1100{ }^{\circ} \mathrm{C}$ and $1200{ }^{\circ} \mathrm{C}$ in an oxidation atmosphere, the sapphires, which were colorless, did not show any obvious color changes. After heat treatment at $1500{ }^{\circ} \mathrm{C}$ in the reduction atmosphere, only samples BG2-1 and BG4-1 showed an obvious blue color, while the remaining samples did not display the expected blue color.

As Figure 7 shows, the blue band of sample BG2-1 was hexagonal. Some parallel banded structures in sample DG1-1 turned blue after heat treatment. Veil-like fillings can be observed, which were caused by sodium borate melting and filling into cracks at a high temperature. Stress cracks were observed around the crystal inclusions, providing evidence that the sapphires were heated (Figure 8). 


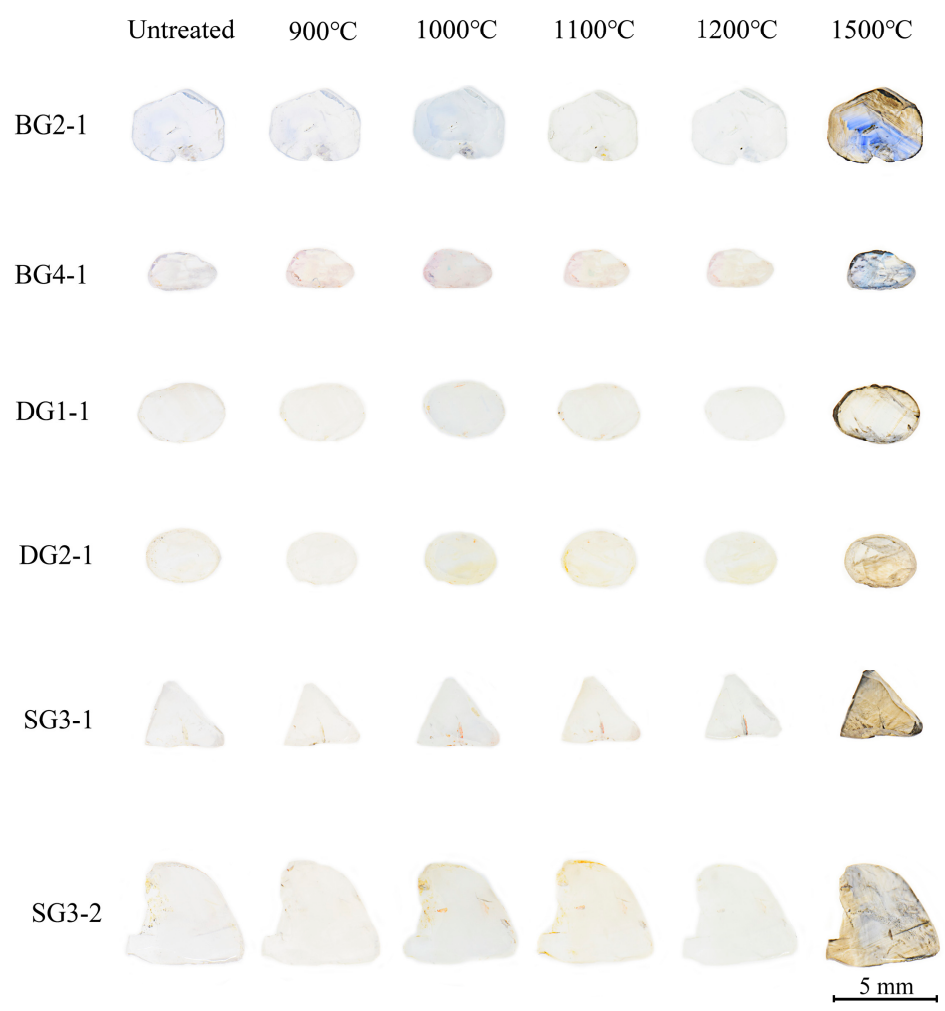

Figure 6. Color changes of the sapphire samples after heat treatment at different temperatures.

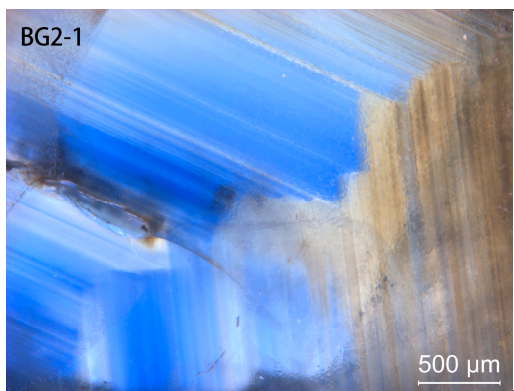

DG1-1

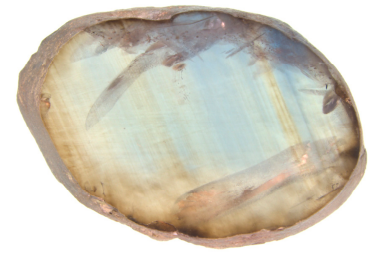

$2 \mathrm{~mm}$

Figure 7. Hexagonal angular (left) and banded (right) blue band after heat treatment.

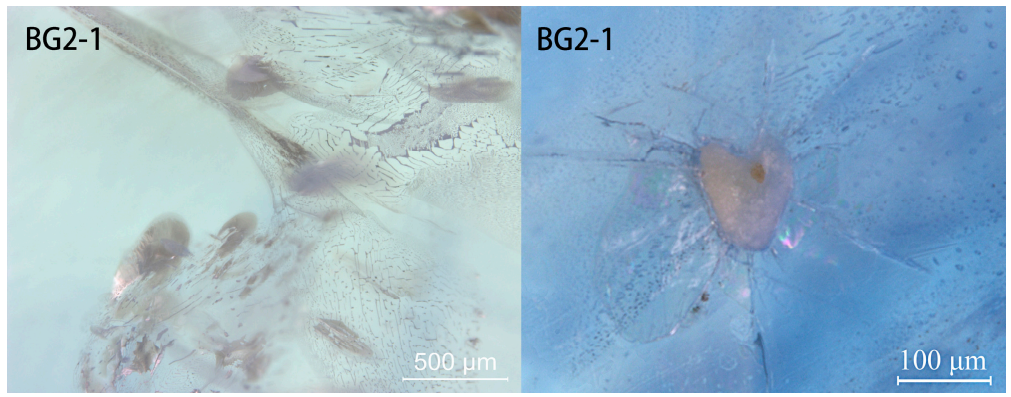

Figure 8. Fractures filled with sodium borate after heat treatment (left) and stress fractures around crystal inclusions (right).

\subsubsection{Infrared Spectroscopy Features of Heated Sapphire Samples}

The peaks of $3309 \mathrm{~cm}^{-1}$ and $3232 \mathrm{~cm}^{-1}$ in the FTIR spectrum are important evidence of heat treatment in sapphires. It is generally believed that the simultaneous occurrence of the $3309 \mathrm{~cm}^{-1}$ and $3232 \mathrm{~cm}^{-1}$ peaks indicates a metamorphic sapphire that was heated at a high temperature [1]. 
Spectra were obtained before and after heating at each temperature (Figure 9), with the following results:

(1) No samples showed a $3309 \mathrm{~cm}^{-1}$ peak after heating at $900{ }^{\circ} \mathrm{C}, 1000{ }^{\circ} \mathrm{C}$ or $1100{ }^{\circ} \mathrm{C}$. After heating to $1200{ }^{\circ} \mathrm{C}$, sample BG2-1 showed a peak of $3309 \mathrm{~cm}^{-1}$, while the other five samples did not. Samples BG2-1, BG4-1 and DG1-1 showed a $3309 \mathrm{~cm}^{-1}$ peak after heating at $1500{ }^{\circ} \mathrm{C}$. Therefore, the occurrence of a $3309 \mathrm{~cm}^{-1}$ peak in the FTIR spectrum is only auxiliary evidence of high temperature heating in Sri Lankan sapphires.

(2) No obvious $3232 \mathrm{~cm}^{-1}$ peak appeared in all samples after heat treatment at each temperature. Therefore, the mere presence/absence of the peak at $3232 \mathrm{~cm}^{-1}$ does not allow us to establish whether the sapphire has been heated.

(3) Sample DG2-1 showed peaks of $2123 \mathrm{~cm}^{-1}$ and $1994 \mathrm{~cm}^{-1}$ when it was not heated, and these two peaks disappeared after heat treatment at $900^{\circ} \mathrm{C}$. This indicates that the existence of the diaspore ( $2123 \mathrm{~cm}^{-1}$ and $1994 \mathrm{~cm}^{-1}$ peaks) is evidence of unheated sapphires.

\subsection{Three-Dimensional Fluorescence Spectroscopy Features of Heated Samples}

The 3D fluorescence spectra were obtained after heating at each temperature (Figure 10).

The changes in fluorescence after heating were as follows:

(1) Fluorescence with emission wavelengths of $420-440 \mathrm{~nm}$. As can be observed from the fluorescence changes of samples BG2-1, DG1-1, DG2-1, SG3-1 and SG3-2 heated at different temperatures, the $420-440 \mathrm{~nm}$ fluorescence tends to increase after heat treatment at $1000^{\circ} \mathrm{C}$ and $1100{ }^{\circ} \mathrm{C}$. This may be consistent with the chalky fluorescence that Hughes (2019) observed in sapphires from Madagascar after low-temperature heat treatment [14].

(2) Fluorescence with emission wavelengths of $470 \mathrm{~nm}$. All samples showed fluorescence with an emission wavelength of $470 \mathrm{~nm}$ after heat treatment at $1500^{\circ} \mathrm{C}$, except SG3-1. This fluorescence did not appear in sapphires without heat treatment or after treatment at a low temperature below $1200{ }^{\circ} \mathrm{C}$. Therefore, it is speculated that the $470 \mathrm{~nm}$ fluorescence is evidence of high-temperature heat treatment in Sri Lankan sapphires. The reason for the absence of $470 \mathrm{~nm}$ fluorescence in sample SG3-1 is unclear.

(3) Fluorescence with emission wavelengths of 540-560 nm and 560-580 nm. This fluorescence almost disappeared after heat treatment. In all samples, the 540-560 nm fluorescence of disappeared after heat treatment at $900{ }^{\circ} \mathrm{C}$, indicating that the fluorescence was greatly affected by the temperature. Since the fluorescence at $540-560 \mathrm{~nm}$ and at 560-580 nm disappeared after heat treatment, the fluorescence at these two sites can be evidence of unheated Sri Lankan sapphires.

(4) Fluorescence with emission wavelengths of $694 \mathrm{~nm}$. This fluorescence appeared after heating at all temperatures, indicating that heat treatment at $1500^{\circ} \mathrm{C}$ and below did not change the environment around $\mathrm{Cr}^{3+}$ significantly. 

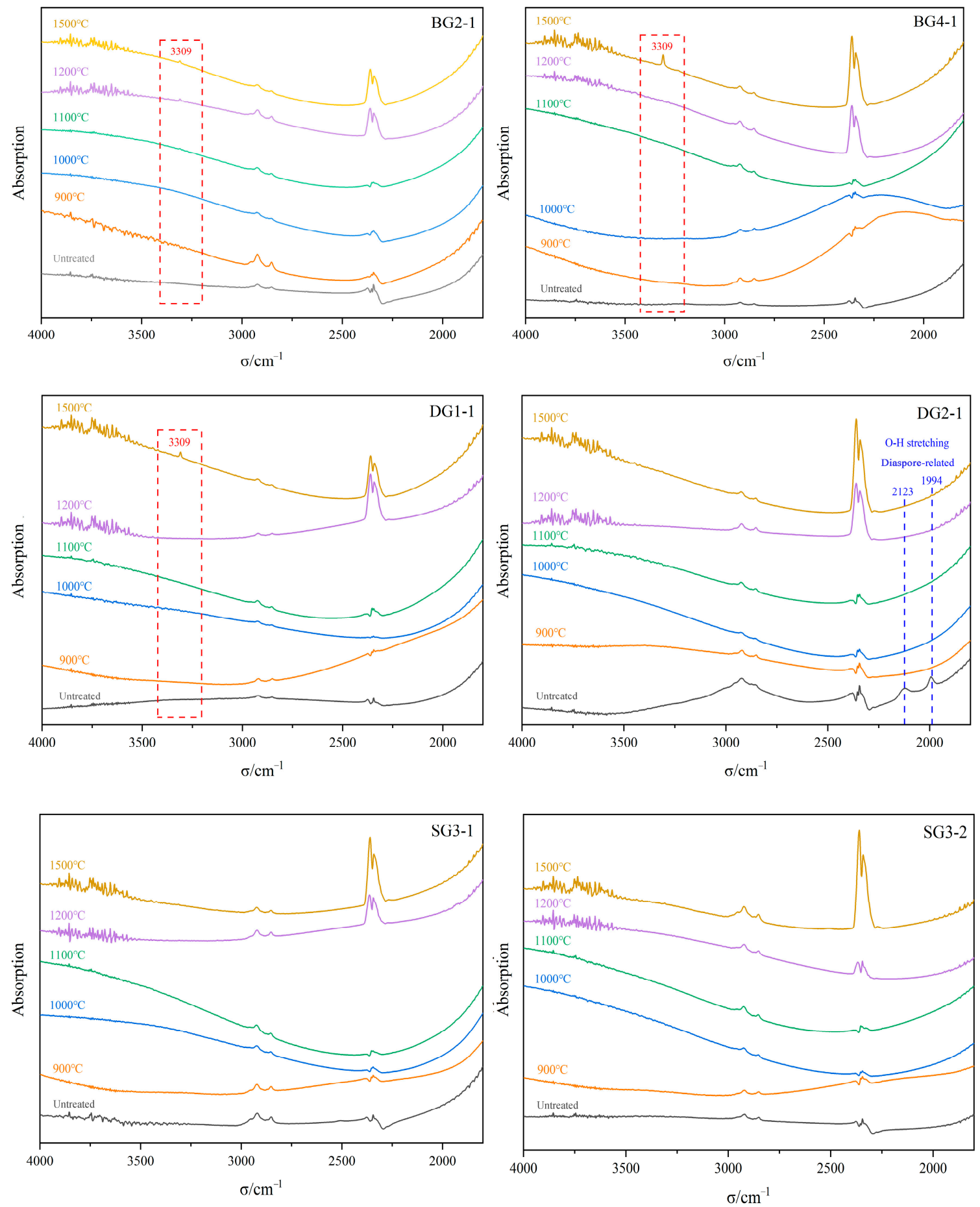

Figure 9. Infrared spectra of sapphire samples after heat treatment at $900{ }^{\circ} \mathrm{C}, 1000{ }^{\circ} \mathrm{C}, 1100{ }^{\circ} \mathrm{C}$, $1200{ }^{\circ} \mathrm{C}$ and $1500{ }^{\circ} \mathrm{C}$.

It is worth noting that Hughes (2017) previously tested the emission spectra and believed that the luminescence center of sapphires after high-temperature heat treatment was located at $415 \mathrm{~nm}$ [1]. The $415 \mathrm{~nm}$ fluorescence was also observed in samples after heat treatment in this study. However, the most obvious difference before and after heating was the $470 \mathrm{~nm}$ fluorescence. Therefore, it is believed that the blue chalky fluorescence that appeared in the sapphires after heat treatment consisted of both the $415 \mathrm{~nm}$ and the $470 \mathrm{~nm}$ fluorescence. 

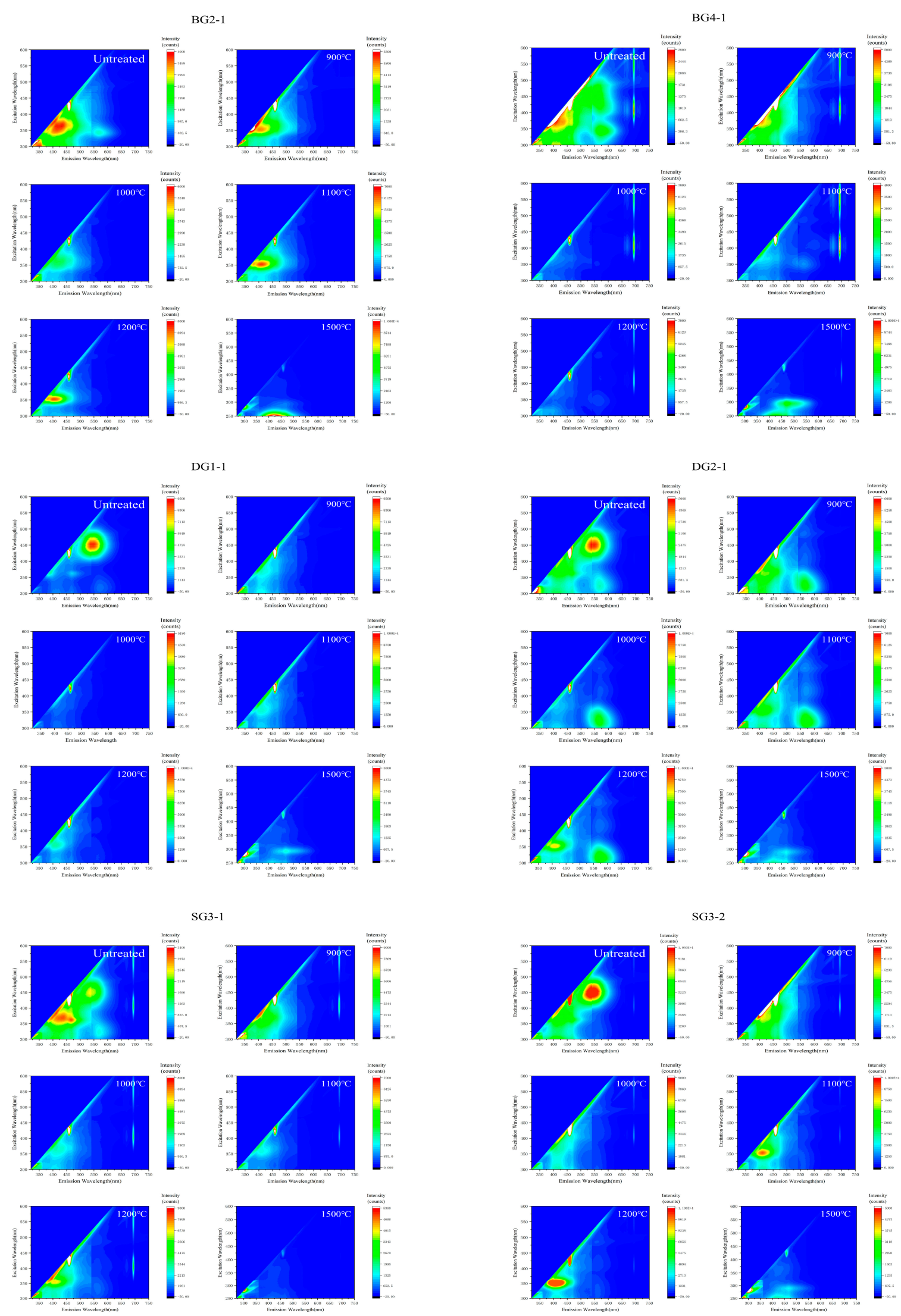

Figure 10. Three-dimensional fluorescence spectra of the sapphire samples before and after heat treatment. 


\section{Conclusions}

In this study, sapphire samples were heated in a temperature range from $900{ }^{\circ} \mathrm{C}$ to $1500{ }^{\circ} \mathrm{C}$. The gemological characteristics, FTIR spectra and 3D fluorescence spectra were tested before and after the heat treatment. The conclusions are as follows:

(1) In our work, no peak of $3232 \mathrm{~cm}^{-1}$ in the FTIR spectra of the heated sapphires was observed. Therefore, FTIR has limitations in judging whether sapphires were heated by using only the $3232 \mathrm{~cm}^{-1}$ peak in the FTIR spectra. The absorption peaks of $2123 \mathrm{~cm}^{-1}$ and $1994 \mathrm{~cm}^{-1}$ indicated that the diaspore disappeared after lowtemperature heat treatment. Thus, the $2123 \mathrm{~cm}^{-1}$ and $1994 \mathrm{~cm}^{-1}$ peaks indicate that the Sri Lankan sapphires were not heated;

(2) According to the 3D fluorescence spectra analysis, the fluorescence with an emission wavelength of 540-560 $\mathrm{nm}$ in untreated samples disappeared after low-temperature heat treatment. Therefore, the existence of 540-560 nm fluorescence is evidence that Sri Lankan sapphires have not been heated;

(3) The $470 \mathrm{~nm}$ fluorescence appeared in samples after heat treatment at $1500{ }^{\circ} \mathrm{C}$. Therefore, the $470 \mathrm{~nm}$ fluorescence is evidence of the high-temperature heat treatment of sapphires. Together with the $415 \mathrm{~nm}$ fluorescence, the $470 \mathrm{~nm}$ fluorescence may form the blue-chalky fluorescence of the Sri Lankan sapphires after heat treatment.

Author Contributions: Writing—original draft preparation, Y.Z.; writing—review and editing, M.C. All authors have read and agreed to the published version of the manuscript.

Funding: This research received no external funding.

Institutional Review Board Statement: Not applicable.

Informed Consent Statement: Not applicable.

Data Availability Statement: All supporting data and computational details are available on written request. These data are stored by the main author of this article.

Acknowledgments: We thank three anonymous reviewers for comments that improved our manuscript.

Conflicts of Interest: The authors declare no conflict of interest.

\section{References}

1. Hughes, R.H.; Manorotkul, W.; Hughes, E.B. Ruby and Sapphire: A Gemologist's Guide; RWH Publishing/Lotus Publishing: Bangkok, Thailand, 2017; pp. 151-158.

2. Crowningshield, R. Developments and Highlights at the Gem Trade Lab in New York: Unusual items encountered. Gems Gemol. 1966, 12, 73.

3. Lucas, A.; Sammoon, A.; Jayarajah, A.P.; Hsu, T.; Padua, P. Sri Lanka: Expedition to the Island of Jewels. Gems Gemol. 2014, 50, 174-201. [CrossRef]

4. Volynets, F.K.; Vorob'ev, V.G.; Sidorova, E.A. Infrared absorption bands in corundum crystals. J. Appl. Spectrosc. 1969, $10,665-667$. [CrossRef]

5. Nicastro, I.; Vertriest, W.; Renfro, N.; Sun, Z.; Palke, A.; Mattlin, P. Purplish pink diaspore reportedly from Afghanistan. Gems Gemol. 2020, 56, 298-301.

6. Ferguson, J.; Fielding, P.E. The origins of the colours of natural yellow, blue and green sapphires. Aust. J. Chem. 1972, 25, 1371-1385. [CrossRef]

7. Smith, G. Evidence for absorption by exchange-coupled $\mathrm{Fe}^{2+}-\mathrm{Fe}^{3+}$ pairs in the near infra-red spectra of minerals. Phys. Chem. Miner. 1978, 3, 375-383. [CrossRef]

8. Marfunin, A.S. Chapter 5: Luminescence. In Spectroscopy, Luminescence and Radiation Centers in Minerals; Springer: Berlin/Heidelberg, Germany; New York, NY, USA, 1979; pp. 141-222. [CrossRef]

9. Lichtman, J.W.; Conchello, J.A. Fluorescence microscopy. Nat. Methods 2005, 2, 910-919. [CrossRef] [PubMed]

10. Zhou, C.; Tsai, T.H.; Sturman, N.; Nilpetploy, N.; Manustrong, A.; Lawanwong, K. Optical Whitening and Brightening of Pearls: A Fluorescence Spectroscopy Study. Gems Gemol. 2020, 56, 258-265. [CrossRef]

11. Tsai, T.-H.; Zhou, C. Fluorescence Spectroscopy for Colored Pearl Treatment Screening. Gems Gemol. 2020, 55, 136.

12. Jiang, X.; Zhang, Z.; Wang, Y.; Kong, F. Gemmological and Spectroscopic Characteristics of Different Varieties of Amber from the Hukawng Valley, Myanmar. J. Gemmol. 2020, 37, 144-162. [CrossRef] 
13. Gaft, M. Modern Luminescence Spectroscopy of Minerals and Materials; Springer: Berlin/Heidelberg, Germany, $2005 ;$ pp. 14-16.

14. Hughes, E.B.; Perkins, R. Madagascar Sapphire: Low-temperature heat treatment experiments. Gems Gemol. 2019, 55, 184-197. [CrossRef] 